\title{
Organization of the human fetal subpallium
}

\author{
Marie-Christin Pauly ${ }^{1,2}$, Máté D. Döbrössy ${ }^{2}$, Guido Nikkhah $^{3}$, Christian Winkler $^{1,4}$ and Tobias Piroth ${ }^{1}$ * \\ ${ }^{1}$ Department of Neurology, University Freiburg - Medical Center, Freiburg, Germany \\ ${ }^{2}$ Department of Stereotactic and Functional Neurosurgery, University Freiburg - Medical Center, Freiburg, Germany \\ ${ }^{3}$ Department of Neurosurgery, University Clinic Erlangen, Erlangen, Germany \\ ${ }^{4}$ Department of Neurology, Lindenbrunn Hospital, Coppenbrügge, Germany
}

\section{Edited by: \\ Alfonso Fairén, University Miguel Hernandez, Spain}

\section{Reviewed by:}

Paul A. Gray, Washington University, USA

Gordon William Arbuthnott, Okinawa Institute of Science and Technology, Japan

\section{${ }^{*}$ Correspondence:}

Tobias Piroth, Department of Neurology, University Freiburg Medical Center, Breisacher Straße 64, 79106 Freiburg, Germany

e-mail: tobias.piroth@

uniklinik-freiburg.de

The subpallium comprises large parts of the basal ganglia including striatum and globus pallidus. Genes and factors involved in the development of the subpallium have been extensively studied in most vertebrates, including amphibians, birds, and rodents. However, our knowledge on patterning of the human subpallium remains insufficient. Using double fluorescent immunohistochemistry, we investigated the protein distribution of transcription factors involved in patterning of the subventricular zone (SVZ) in the human forebrain at late embryonic development. Furthermore, we compared the development of cortical and striatal precursors between human fetal brain and E14 and E16 fetal rat brains. Our results reveal that DLX2 marks SVZ precursors in the entire subpallium. Individual subpallial subdomains can be identified based on co-expression of DLX2 with either PAX6 or NKX2-1. SVZ precursors in the dorsal LGE and preopto-hypothalamic boundary are characterized by DLX2/PAX6 co-expression, while precursors in the MGE and preoptic region co-express DLX2/NKX2-1. SVZ precursors in the ventral LGE are DLX2(+)/PAX6(-)/NKX2-1(-). In terms of staging comparisons, the development of the corpus striatum in the human fetal brain during late embryonic stages corresponds well with the development of the striatum observed in E14 fetal rat brains. Our study demonstrates that the pattern underlying the development of the subpallium is highly conserved between rodents and humans and suggests a similar function for these factors in human brain development. Moreover, our data directly influence the application of ganglionic eminence derived human tissue for cell therapeutic approaches in neurodegenerative disorders such as Huntington's disease.

\section{Keywords: subpallium, ganglionic eminence, striatum, development, patterning}

\section{INTRODUCTION}

During embryonic development, the future forebrain is already determined by expression of OTX2 in the neuroectoderm at the gastrula stage (Simeone et al., 1993). During the following neurulation the central nervous system - the so-called neural tube - forms by budding off from the ectoderm. The neural tube is divided into four longitudinal zones along the dorsoventral axis (floor, basal, alar, and roof plate). Furthermore, the anterior part of the neural tube that will develop into the encephalon is divided into initially three transverse zones along the anterior-posterior axis: the anterior prosencephalon (forebrain), the mesencephalon (midbrain), and the posterior rhombencephalon (hindbrain). Prosencephalon and rhombencephalon will further divide into subdomains while the mesencephalon does not subdivide.

Our knowledge of mechanisms involved in controlling neural progenitor region patterning and brain development is almost completely derived from animal models. In contrast to earlier distinctions which were solely based on anatomic landmarks, the current widely accepted model of the prosencephalic subdivision provided by (Puelles and Rubenstein, 2003) relies on gene expression patterns of transcription factors (mainly of DLX, NKX, LHX, and PAX family members) in subventricular zone (SVZ) precursors of the particular area. According to this model, the prosencephalon is divided into the secondary prosencephalon (rostral) which represents the entire prechordal portion of the neural tube and into the caudal diencephalon (Puelles and Rubenstein, 2003) The caudal diencephalon is further subdivided into three so-called prosomeres (p1-p3) which will develop into habenular, thalamus, and prethalamus (PTh; Martinez-Ferre and Martinez, 2012). The secondary prosencephalon comprises the rostral diencephalon (hypothalamus) and the entire telencephalon. It is further divided into an evaginated and a non-evaginated domain (Puelles and Rubenstein, 2003). The evaginated secondary prosencephalon comprises the pallium, the lateral, and medial division of the ganglionic eminence (LGE respectively, MGE) and furthermore the optic vesicles. The pallium will develop into cortex and large parts of the limbic system, while LGE and MGE will give rise to the basal ganglia [striatum and globus pallidus (GPe)]. The ventral telencephalon (subpallium) and pallium are separated by a longitudinal boundary - the pallial-subpallial boundary (PSB) which proceeds dorsally of the LGE. In addition to the evaginated secondary prosencephalon, the non-evaginated secondary prosencephalon comprises the telencephalic stalk and the hypothalamus [except the optic stalk (os)]. The telencephalic stalk includes the preoptic region $(\mathrm{PO})$ and the preopto-hypothalamic boundary 
$(\mathrm{POH})$. The $\mathrm{POH}$ is the boundary that separates subpallium and hypothalamus (Flames et al., 2007). The hypothalamus, in turn, is further subdivided into the rostral (alar) and a caudal (basal) domain.

Comparative expression analyses revealed that the prosomeric subdivision is conserved among all vertebrates (Moreno et al., 2009; Moreno and González, 2011). However, our knowledge on the genoarchitecture of the human prosencephalon remains insufficient. Various studies described the expression transcription factors involved in telencephalic patterning in the human fetal brain, but these studies mainly focused on corticogenesis and development of cortical interneurons (Terzić and Saraga-Babić, 1999; Lindsay etal., 2005; Bystron etal., 2006; Métin etal., 2007; Jakovcevski et al., 2011). However, systematic analyses regarding subdivisions and their boundaries are missing. In the present study, the protein expression of markers determining the secondary prosencephalon were analyzed in human fetuses at late embryonic stages (around 50-54 days post fertilization, dpf) and E14.0 and E16.0 rat fetuses were taken as reference. Our results show that the protein expression patterns of regional restricted transcription factors in the developing brain are conserved between humans and rodents. Furthermore our results show that the neuronal differentiation dynamics differ between rodents and humans.

\section{MATERIALS AND METHODS TISSUE COLLECTION}

All experiments comprising human fetal tissue samples were in agreement with the German law. Experiments with human tissue samples were approved by the ethical committee of the University Freiburg. Human fetal tissue from routine elective abortions was collected with approved consent of the donating pregnant woman within the Multicentric Intracerebral Grafting in Huntington's disease (MIG-HD) clinical transplantation program (ClinicalTrials.gov Identifier: NCT00190450). This paneuropean trial aims at intrastriatal transplantation of human fetal ganglionic eminence derived progenitor cells for the treatment of Huntington's disease (HD). Tissue used in the present study was obtained in cases where a clinical application was not possible. Fetal tissue samples were collected in Hank's balanced salt solution (HBSS) without $\mathrm{Mg}^{2+}, \mathrm{Ca}^{2+}$, or Dulbecco's modified Eagle medium (DMEM; all purchased from Life Technologies, Grand Island, NY, USA) medium and stored at $4^{\circ} \mathrm{C}$. The age of the fetuses was assessed morphometrically as described by Evtouchenko and collaborators (Evtouchenko et al., 1996). Evaluation of the health status of the pregnant woman was routinely performed by serological sample analysis for the human immune deficiency virus (HIV), hepatitis virus type $\mathrm{B}$ and $\mathrm{C}$ (HBV and $\mathrm{HCV}$ ) and toxoplasmosis. For this study, brains from three human fetuses of 50-54 dpf measuring 23.5, 28.0, and $28.5 \mathrm{~mm}$ CRL were analyzed; two more human fetal brains of earlier developmental stages were examined beforehand to test the specificity of the antibody staining.

All animal experiments were approved by the local authorities beforehand. Male and female Sprague-Dawley rats were purchased from Charles River Laboratories (Sulzfeld, Germany) and housed in the animal facility of the University Freiburg Medical
Center. Animals were kept under conventional housing conditions. The day after mating was considered as embryonic day 0 (E0). At the desired embryonic age, pregnant dams were sacrificed by i. p. injection of $150 \mathrm{mg} / \mathrm{kg}$ ketamine (Bayer, Leverkusen, Germany) and $15 \mathrm{mg} / \mathrm{kg}$ xylazine (Rompun ${ }^{\circledR}$; Bayer) and additional cardiotomy. The abdomen of the animal was disinfected using 70\% ethanol, and abdominal muscles were opened. The uterus was dissected and rinsed in sterile phosphate-buffered saline (PBS). Embryos were removed from the uterus and stored in HBSS or DMEM. The litter sizes usually ranged between 12 and 15 fetuses per dam. CRL of the fetuses was measured under a stereomicroscope and the age of the fetuses was calculated using embryonic staging data by Torres et al. (2008).

\section{IMMUNOHISTOCHEMISTRY}

Fresh tissue samples from fetal CNS were snap frozen in TissueTek O.C.T. compound (Sakura, Leiden, the Netherlands) in methyl butane (Merck, Darmstadt, Germany) that was cooled in a mixture of dry ice and ethanol. For human tissue samples, the CNS was dissected prior to snap freezing, whereas rat fetuses were completely frozen. Tissue was sectioned on a cryostat in coronal direction at $12 \mu \mathrm{m}$ in eight series. Sections were mounted on Superfrost plus slides (R. Langenbrinck, Emmendingen, Germany). Fresh frozen sections were dried at $37^{\circ} \mathrm{C}$ for $20-30 \mathrm{~min}$. For transcription factor staining, sections were fixed in acetone pre-cooled on dry ice for $10 \mathrm{~min}$ followed by extensive drying for $1 \mathrm{~h}$. For DARPP32 staining, sections were fixed in 4\% paraformaldehyde (PFA; Merck) in PBS. To prevent leakage of the antibody solution, glass slides were circulated with a silicone pen (Dako, Hamburg Germany). Sections were washed three times in PBS/0.1\% Tween-20 (Calbiochem, Bad Soden, Germany; PBST), and blocked in PBS/0.2\% Triton X-100 (Sigma Aldrich)/10\% serum, species specific to the host of the secondary antibody. Primary antibody was diluted in antibody solution containing PBS/0.2\% Triton X-100/2\% serum for $2 \mathrm{~h}$ at RT, or overnight at $4^{\circ} \mathrm{C}$. Primary antibodies and their specific epitopes, as well as the dilution and product information are listed in Table 1. The specificity of the antibodies has been demonstrated by the manufacturer and all antibodies are recommended to detect their specific target of human and rodent origin. However, we performed a protein sequence BLAST analysis (blastp) to provide the degree of homology to the human and rat protein. Where possible primary antibodies directed against the human protein were used. After incubation, the primary antibody solution was washed off, and secondary antibodies conjugated with either Alexa-488 or Alexa-568 fluorescent dyes (all obtained from Life Technologies) including DAPI as nuclear counter stain diluted in antibody solution were incubated for $2 \mathrm{~h}$ at RT. Afterwards, sections were washed three times in PBS/0.1\% Tween-20. Acetone-fixed slides were post-fixed in 4\% PFA (Merck). Sections were mounted with fluorescent mounting medium (Dako) and stored at $4^{\circ} \mathrm{C}$ in the dark. Controls including no-primary antibody have been performed to provide evidence of the antibody specificity.

\section{CRESYL VIOLET STAINING}

One whole series was stained with a standard cresyl violet staining. Briefly, sections were dried, fixed in $4 \%$ PFA in PBS, rinsed in 
Table 1 | Antibodies validated to work on human and rat fetal tissue samples.

\begin{tabular}{|c|c|c|c|c|c|}
\hline Antibody & $\begin{array}{l}\text { Distributor (ordering } \\
\text { information) }\end{array}$ & Dilution & Epitope & $\begin{array}{l}\text { Homology to } \\
\text { human, } \%\end{array}$ & $\begin{array}{l}\text { Homology to } \\
\text { rat, \% }\end{array}$ \\
\hline Anti-DLX2 & Santa Cruz (sc-18140) & $1: 50$ & C-terminus of human DLX2 & 100 & 93 \\
\hline Anti-FOXP1 & abcam (ab16645) & $1: 500$ & Amino acid 650 to $\mathrm{C}$-terminus of human FOXP1 & 100 & 100 \\
\hline Anti-NKX2-2 & $\begin{array}{l}\text { Developmental studies } \\
\text { hybridoma bank }\end{array}$ & $3 \mu \mathrm{g} / \mathrm{ml}$ & Amino acid $1-223$ of chick PAX6 & 99 & 92 \\
\hline Anti-PAX6 & Santa Cruz (sc-32766) & $1: 100$ & Amino acid $1-206$ of human PAX6 & 100 & 99 \\
\hline
\end{tabular}

water and incubated in $0,1 \%$ cresyl violet acetate solution at $37^{\circ} \mathrm{C}$ for $20 \mathrm{~min}$. Afterwards, sections were again rinsed in water, dehydrated in ethanol, cleared in xylol and mounted with histofluid mounting medium (Marienfeld-Superior, Lauda-Königshofen, Germany). Cresyl violet stained series were used as reference for brain morphology.

\section{MICROSCOPY AND IMAGE COMPOSITION}

Immunohistochemical sections were analyzed using an AX70 microscope (Olympus, Tokyo, Japan) that was equipped with a CC-12 camera and CellP imaging software (Olympus). Independent replicates of minimum three different donors were analyzed for all experiments. Representative single and double immune fluorescence stained sections were photographed with a $4 \times$ objective [numerical aperture (NA) 0.13] for human and E16 rat, a $10 \times$ objective (NA 0.3) for E14 rat, a $20 \times$ objective (NA 0.5) for details and a $100 \times$ (NA 1.3 oil immersion) objective for single cells. Cresyl violet stained sections were photographed using a $1.25 \times(\mathrm{NA} 0.04)$ light microscopy objective. For images of whole sections, individual images photographed with a $10 \times$ objective were imported to Illustrator CS6 (Adobe Systems, San José, CA, USA) sequentially and aligned manually. The DAPI image was composed first; next, the file association was changed to the corresponding red or green fluorescent image. Histogram-controlled linear level adjustment, brightness and contrast adaptation, and cropping were performed using Photoshop CS6 (Adobe Systems). Images of brain areas without specific antibody signal were used as control for image adjustment. Figures were composed with Illustrator CS6 (Adobe Systems). The nomenclature of the fetal brain anatomy follows that used in previous studies on mammalian prosencephalon mapping (Puelles and Rubenstein, 2003; Flames et al., 2007; Moreno et al., 2009).

\section{RESULTS}

The genoarchitecture of the subpallium as well as its dorsal and caudal boundaries was analyzed by co-immunohistochemistry of 50-54 dpf human fetuses (Figures 1,2). This time point represents the late embryonic stage of development (O'Rahilly and Müller, 2006). An overview of a typical coronal section of the subpallium stained with cresyl violet is provided in Figure 1A. Furthermore, we aimed to correlate neurogenesis in human fetuses at that stage with the development of the rat. Therefore, we compared the expression of mitotic and post-mitotic precursor markers in the striatal and cortical anlage between human fetuses and rat fetuses derived from embryonic day E14.0 and E16.0 (Figure 3). A schematic representation of our results is presented in Figure 4.

\section{DLX2 AND NKX2-1 CHARACTERIZE SUBPALLIAL REGIONS IN THE HUMAN FETAL BRAIN}

In the human fetal subpallium, DLX2-positive cells were detected in the SVZ of LGE, MGE, PO, and $\mathrm{POH}$ (Figure 1). In the ganglionic eminence, DLX2-positive cells were detected in a stripe at the ventricular portion of the SVZ in the LGE, ending abrupt at the PSB (Figures 1B,C,E,F dotted line, Figure 1G). While NKX2-1-positive cells were not observed in the LGE, MGE, and PO are characterized by DLX2/NKX2-1 co-expression (Figures 1B,D,H-J). Post-mitotic expression of NKX2-1 was detected in the external segment of the GPe (Figure 1K). In turn, DLX2/NKX2-1 co-expressing cells were not detected in the $\mathrm{POH}$ (Figures 1K,L). Coincidently with the disappearance of NKX2-1 domain, the fusion of the anterior diencephalon at the telencephalic-diencephalic boundary was observed, indicating that in the human fetus, the boundary between subpallium and hypothalamus is not only morphologically, but also molecularly defined. In turn, no DLX2-positive or NKX2-1 positive cells were detected in the pallium at this stage (Figure 1M).

\section{PAX6 AND DLX2 DETERMINE THE BOUNDARIES OF THE SUBPALLIUM IN THE HUMAN FETAL BRAIN}

Analysis of PAX6 and DLX2 co-expression allowed determining regions adjacent to the subpallium (Figure 2): PAX6-positive cells were detected in the SVZ of the pallium (Figures 2A,C,D,F). Cells co-expressing PAX6/DLX2 were detected in the dorsal LGE (dLGE) but not in the ventral LGE (vLGE) where PAX6 positive cells were not observed (Figures 2A-G). Thus, PAX6 divides the human LGE into two distinct domains (Figures 2A,D dashed line). In turn, the position of the PSB is determined by the 


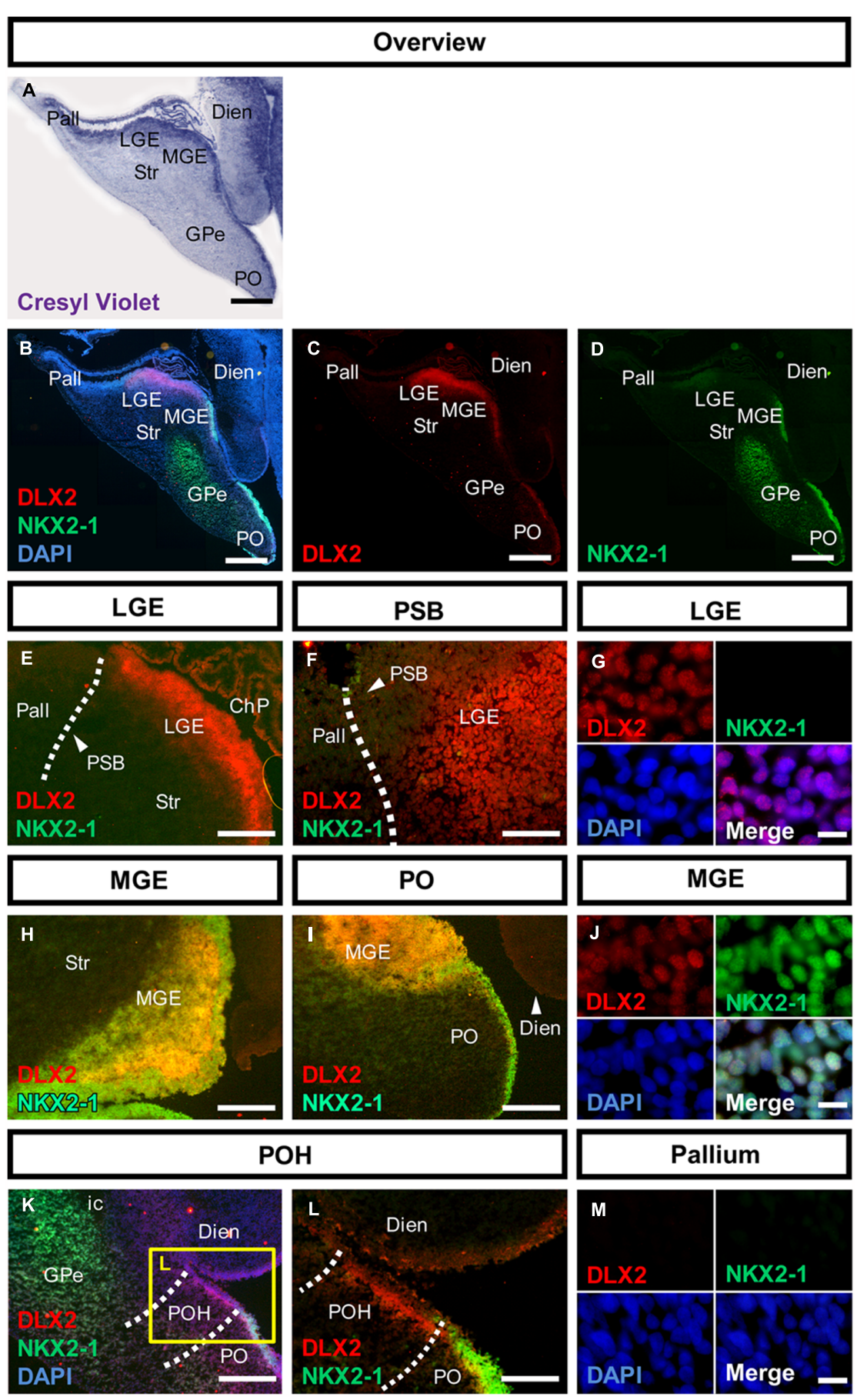

FIGURE 1 | Molecular characterization of the human subpallium. (A) Photomicrographs of cresyl-violet coronal human subpallial sections. (B-D) Photomicrographs of sections stained against DLX2 (red) and NKX2-1 (green) and DAPI (blue). (E,F) DLX2-positive cells were detected in the LGE and end abruptly at the PSB. (G) Verification of nuclear DLX2 signal in the LGE and absence of NKX2-1. (H-J) DLX2/NKX2-1 co-expressing cells were detected in MGE and PO. $(\mathbf{K}, \mathbf{L})$ Cells within the boundary between subpallium and hypothalamus express DLX2 and lack NKX2-1. (M) Neither DLX2-positive nor NKX2-1 positive cells were detected in the pallium. Abbreviations: CGE, caudal ganglionic eminence; ChP, choroid plexus; DARPP32, dopamine- and cAMP-regulated phosphoprotein, 32 kDa; Dien, diencephalon; dLGE, dorsal part of the lateral ganglionic eminence; DLX2, distal-less homeobox protein 2; FOXP1, forkhead box protein P1; GPe, external segment of the globus pallidus; LGE, lateral ganglionic eminence; $L V$, lateral ventricle; MGE, medial ganglionic eminence; NKX2-1, homeobox protein NK-2 homolog A; NKX2-2, homeobox protein NK-2 homolog B; os, optic stalk; Pall, pallium; PAX6, paired box protein 6; PO, preoptic area; $\mathrm{POH}$, preopto-hypothalamic boundary; PSB, pallial-subpallial boundary; PTh, prethalamus; PVN, paraventricular nucleus of the hypothalamus; SATB2, special AT-rich sequence-binding protein 2; SP, cortical subplate; SPV, supraopto-paraventricular region of the hypothalamus; Str, striatum; VLGE, ventral part of the lateral ganglionic eminence; ZLI, zona limitans intrathalamica. Scale bars: $1 \mathrm{~mm}$ in $\mathbf{A}-\mathbf{D} .500 \mu \mathrm{m}$ in $\mathbf{E}, \mathbf{H}, \mathbf{I}, \mathbf{K} ; 200 \mu \mathrm{m}$ in $\mathbf{L}$; $100 \mu \mathrm{m}$ in $\mathbf{F} ; 10 \mu \mathrm{m}$ in $\mathbf{G}, \mathbf{J}, \mathbf{M}$. 


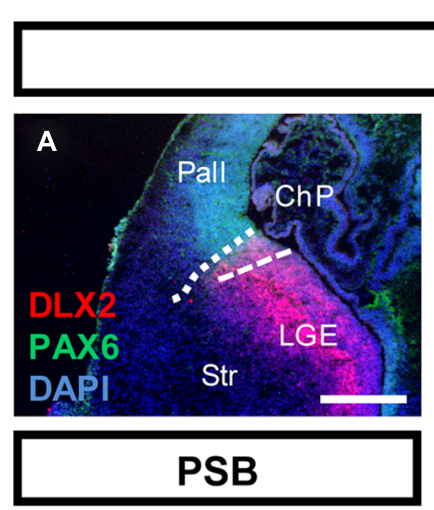

\section{Pallium and LGE}
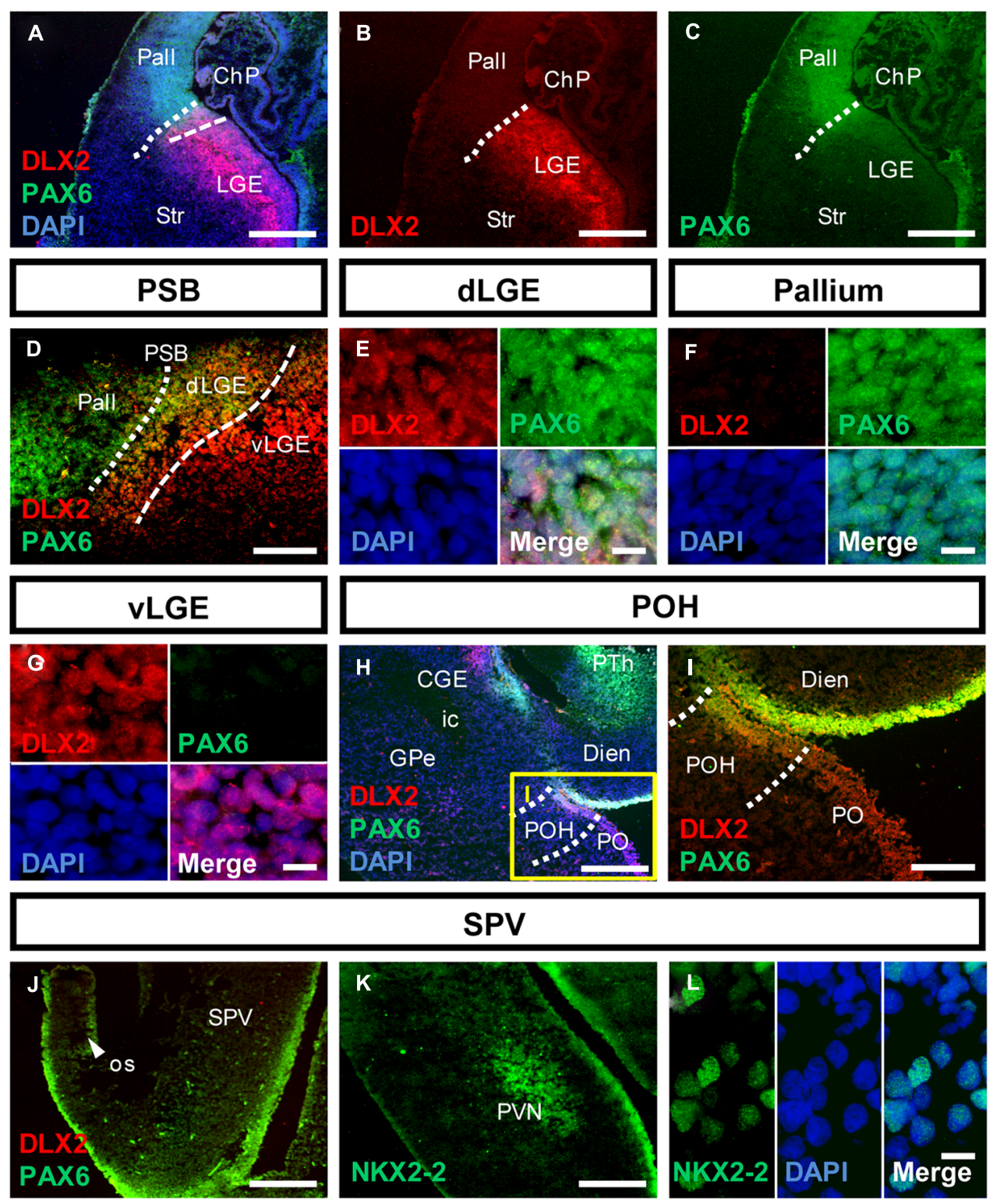

SPV
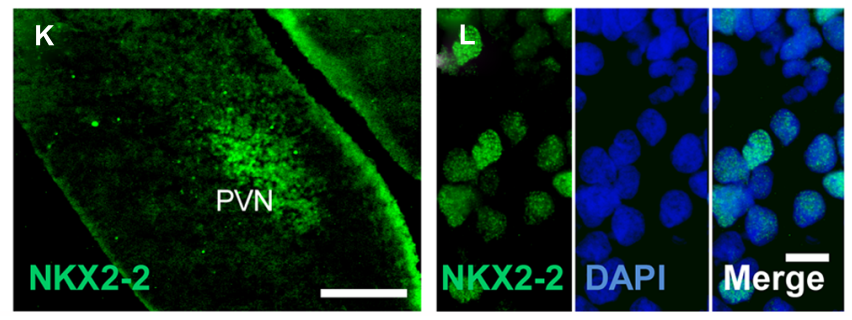

FIGURE 2 | Molecular identity of the pallial-subpallial boundary and the preopto-hypothalamic boundary in the human fetal brain.

(A-C) Photomicrographs of coronal human subpallial sections stained against DLX2 (red) and PAX6 (green); (D) the dLGE co-expresses DLX2 and PAX6. (E-G): co-expressing DLX-2 positive and PAX6-positive cells were detected in the dLGE but not in the Pallium or LGE. $(\mathbf{H}, \mathbf{I})$ The boundary between subpallium and hypothalamus is characterized by
DLX2/PAX6 co-expression (J-L) photomicrograph of the alar hypothalamus stained against (J) PAX6 (green) and DLX2 (red) and $(\mathbf{K}, \mathbf{L})$ NKX2-2 (green). (J) The alar hypothalamus is characterized by PAX6. (K,L) NKX2-2 is expressed in the SVZ of the AB boundary and in post-mitotic cells giving rise to the PVN. Abbreviations see Figure 1 Scale bars: $500 \mu \mathrm{m}$ in $\mathbf{A}-\mathbf{C}, \mathbf{H}, \mathbf{J}, \mathbf{K} ; 200 \mu \mathrm{m}$ in $\mathbf{I} ; 100 \mu \mathrm{m}$ in $\mathbf{D} ; 10 \mu \mathrm{m}$ in $\mathbf{E}-\mathbf{G}, \mathbf{L}$
PAX6-positive/DLX2-negative domain (pallium) and the PAX6positive/DLX2-positive (dLGE) domain (Figures 2A-D, dotted line). Caudally, at the boundary between subpallium and hypothalamus, PAX6/DLX2 co-expression was detected in the $\mathrm{POH}$ (Figures 2H,I). PAX6 expression was furthermore detected in the alar hypothalamus. Here, it was expressed in the supraoptoparaventricular region (SPV) and the evaginating os, as well as in the retina (Figure 2J and not shown). The transcription factor NKX2-2 is a target of the Shh morphogen and involved in establishing the alar-basal (AB) boundary (Pabst et al., 2000). In the human fetus, NKX2-2 expression was found in SVZ precursors along the hypothalamic AB boundary, from where numerous cells migrate outward to generate the paraventricular nucleus of the hypothalamus (PVN; Figures 2K,L). 


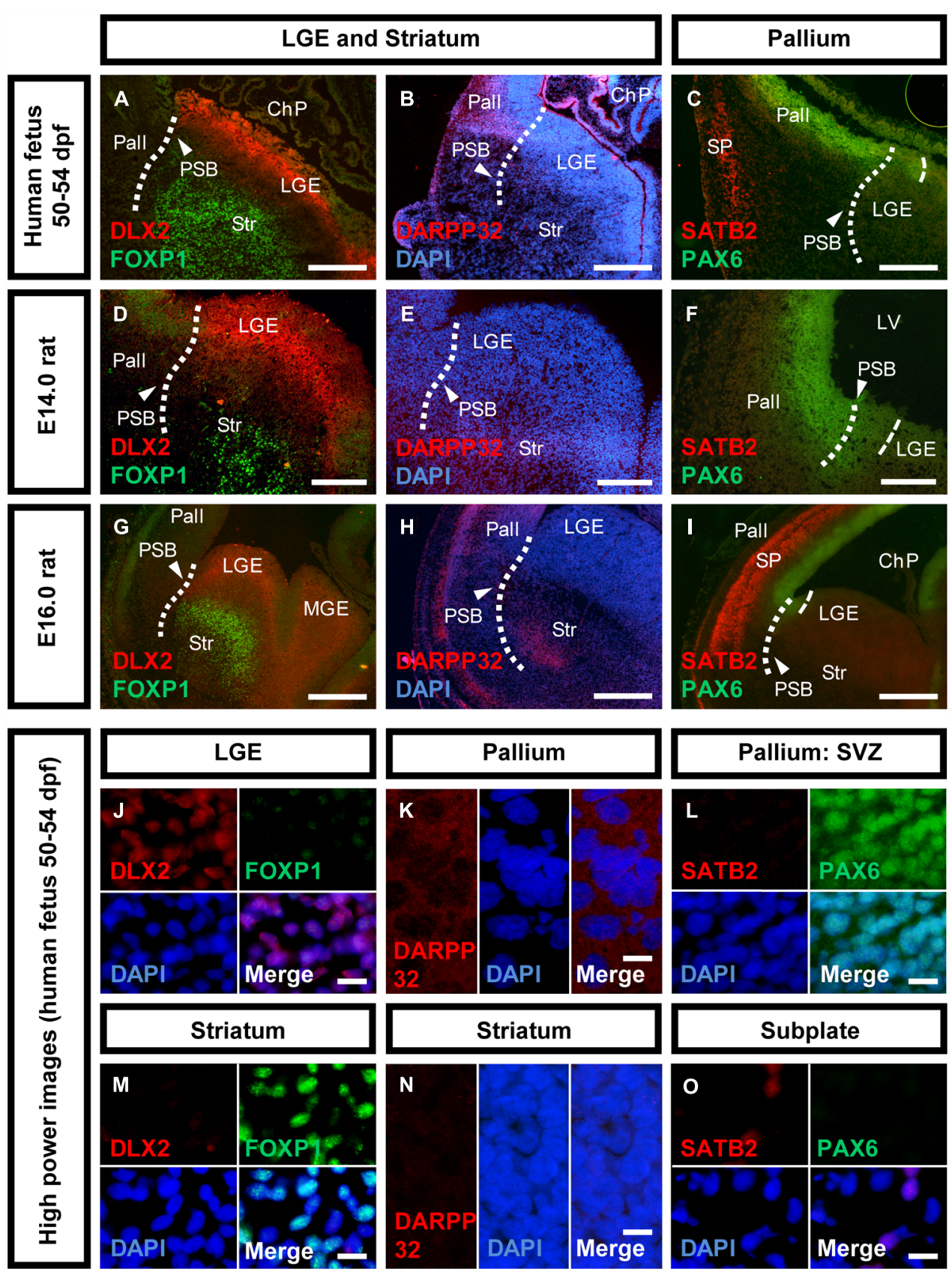

FIGURE 3 | Neuronal maturation of the striatum versus cortex in human and rat. Photomicrographs of coronal sections of the human and rat telencephalon. (A,D,G,J,M) Expression of DLX2 (red) and FOXP1 (green) in the human, E14.0 and E16.0 rat LGE and striatum. $(\mathbf{B}, \mathbf{E}, \mathbf{H}, \mathbf{K}, \mathbf{N})$ Expression of DARPP32 (red) and the nuclear counter stain DAPI (blue) in the human, E14.0 and E16.0 rat pallium, and striatum. (C, F, I,L, O) Expression of SATB2 (red) and PAX6 (green) in the human, E14.0 and E16.0 rat pallium, and cortical subplate. Abbreviations see Figure 1. Scale bars: $500 \mu \mathrm{m}$ in A-C,G-I; $200 \mu \mathrm{m}$ in $\mathbf{D}-\mathbf{F} ; 10 \mu \mathrm{m}$ in $\mathbf{J}-\mathbf{O}$

\section{DIFFERENT MATURATION DYNAMICS IN HUMAN AND RAT}

To analyze the maturation of telencephalic structures precursor markers and post-mitotic markers were analyzed in the human fetal brain and compared with rat fetuses at embryonic day E14.0 and E16.0 (Figure 3). Striatal precursors located in the mantle zone $(\mathrm{MZ})$ of the human LGE stained positive for FOXP1 (Figure 3A). The lack of DLX2/FOXP1 co-expression suggests that these cells are post-mitotic juvenile neurons (Figures 3J,M). To determine the developmental stage of the striatum, the expression of DLX2 and FOXP1 was also analyzed in E14.0 and E16.0 rat fetuses (Figures 3D,G). Both, E14.0 and E16.0 ganglionic eminence stained positive for DLX2 in the SVZ and FOXP1 in the $\mathrm{MZ}$, indicating the presence of mitotic precursors and juvenile striatal neurons. To analyze whether mature striatal neurons are 
present in the 50-54 dpf human fetus, we analyzed the expression of DARPP32 (Figures 3B,E,H). DARPP32-positive cells were detected in the human pallium, but not in the striatum (Figures 3B,K,N). In the E14.0 rat brain, DARPP32 expression was not detected in any telencephalic region (Figure $3 \mathbf{E}$ ). In the E16.0 rat fetus, DARPP32-positive cells were detected in a small group of cells within the developing ventral telencephalon located at the outer margin of the future striatum as well as in a narrow band in the outer cortical layer (Figure $3 \mathbf{H}$ ). Additionally, differences between human and rat development were observed in the fetal pallium. The expression of the cortical subplate (SP) marker SATB2 was observed in a domain dorsal of the PSB but it was not expressed throughout the dorsal telencephalon (Figure 3C). We did not observe cells co-expressing PAX6/SATB2 in the pallial SVZ or cortical SP (Figures 3L,O). The E14.0 pallium did not stain positive for SATB2 while PAX6 was highly expressed (Figure 3F). In contrast, in the E16.0 rat brain, SATB2-positive cells were detected in the upper layer cortex indicating a high number of cortical precursors (Figure 3I). The expression domain of SATB2 is much larger as observed in the human fetus and comprises the entire dorsal telencephalon. As in the E14.0 fetal rat brain, pallial SVZ precursors in the human fetal brain were positive for PAX6 although the expression was reduced compared to E14.0.

\section{DISCUSSION}

In the present study, we provide evidence that the genoarchitecture of the human fetal forebrain shares many features with that of developing rodents. An overview of the results from the present study is shown in Figure 4. Our data further reveal that the progression of cortical and basal ganglia development differs between human and rodents.

The SVZ of the entire human subpallium is characterized by DLX2, whereas, in turn, PAX6 characterizes the SVZ of the human pallium and large parts of the rostral diencephalon. Subpallial subdomains can be further distinguished based on co-localization between DLX2/NKX2-1 and DLX2/PAX6, respectively. MGE and PO are characterized by the co-localization of DLX2 and NKX21, while the dorsal-most part of the LGE and the POH can be identified based on DLX2 and PAX6 co-localization as well as by the lack of NKX2-1 expression. The rostral-most hypothalamic domain called SPV is characterized by PAX6, Caudal and rostral hypothalamus is separated by the $\mathrm{AB}$ boundary which is characterized by NKX2-2, post-mitotic expression of NKX2-2 was also detected in the PVN.

\section{THE MAMMALIAN SUBPALLIUM}

The genoarchitecture of the subpallium has been thoroughly studied in many vertebrates including mammals, birds, reptiles,

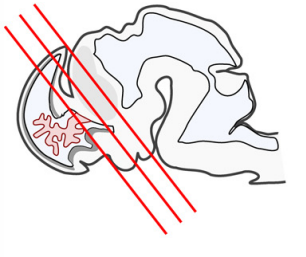

A Telencephalon

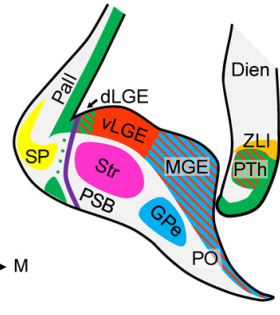

NKX2-1

NKX2-2

SATB2

FOXP1

co-localization

D

Transcription factor patterns in the developing human forebrain
B $\begin{array}{ll}\text { Telencephalic- } & \text { Telencephalon and } \\ \text { diencephalic-boundary } & \text { alar diencephalon }\end{array}$
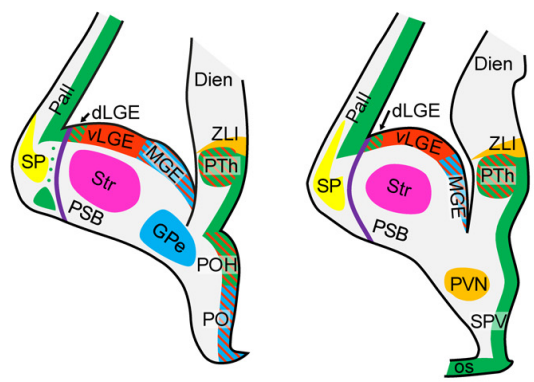

\begin{tabular}{|c|c|c|c|c|c|c|c|}
\hline \multirow[b]{2}{*}{ Structure } & \multicolumn{5}{|c|}{ Telencephalon } & \multicolumn{2}{|c|}{ Hypothalamus } \\
\hline & Pallium & dLGE & VLGE & MGE & PO & POH & SPV \\
\hline PAX6 & & & & & & & os \\
\hline \multicolumn{8}{|l|}{ DLX2 } \\
\hline NKX2-1 & & & & $\mathrm{GPe}$ & & & \\
\hline NKX2-2 & & ? & & & & & PVN \\
\hline
\end{tabular}

region-specific localization

FIGURE 4 | Schematic representation of the marker expression in the human fetal forebrain. (A-C) Schematic coronal sections of the telenecephalon, and alar dienecephalon. Section planes are indicated by red lines in the localizer on the left side. (D) Transcription factors expressed in subventricular precursors define molecular boundaries in the fetal human brain. Abbreviations see Figure 1. 
amphibians, and fish (Cobos etal., 2001; Flames etal., 2007; Métin et al., 2007; Moreno et al., 2008). Phylogenetic comparisons revealed an evolutionary conserved blueprint for the basal ganglia and amygdaloid complex among jawed vertebrates (Moreno et al., 2009; Medina et al., 2011). Protein expression data from the present study reveals a conserved pattern of subpallial neurogenesis in the human fetal brain. The subpallium is characterized by high expression of distal-less related (DLX) transcription factors (Robinson et al., 1991; Bulfone et al., 1993; Price, 1993; Corbin et al., 2000; present study). The LGE differs from MGE and PO by lacking expression of NKX2-1 (Sussel et al., 1999; Xu et al., 2008; present study). The rodent LGE progenitor domain is further subdivided into a dorsal and ventral domain based on PAX6 expression (Stoykova et al., 2000; Tole et al., 2005; Flames et al., 2007). Progenitors from the PAX6-positive dLGE migrate rostral to the olfactory tubercle and ventral to the extended amygdala, whereas progenitors from the PAX6-negative vLGE generate the dorsal (caudate-putamen) and ventral striatum (accumbens nucleus; Yun etal., 2003; Tole etal., 2005; García-López etal., 2008). The MGE it characterized by high expression of NKX21. Similar to the LGE, the MGE gives rise to multiple neuron types in the forebrain (Sussel et al., 1999; Du et al., 2008; Xu et al., 2008). The main projection neurons generated by the MGE are GABAergic neurons of the GPe (Flandin et al., 2010; present results). The GPe neurons are generated early in development. Following GPe neurogenesis, the MGE serves as main source of GABAergic interneurons in the telencephalon (Hernández-Miranda et al., 2010). The PO expresses high levels of NKX2-1 and DLX2, too, but can be distinguished from the ganglionic eminence by high expression levels of Shh as well as the by the lack of Gsx2 expression (Flames et al., 2007; García-López et al., 2008; Bardet et al., 2010; present data). The PO gives rise to the lateral and medial portion of the preoptic nucleus and furthermore to the majority of forebrain cholinergic neurons (Ch1-4, striatal interneurons; Thal et al., 1992; Marin et al., 2000; Elshatory and Gan, 2008; García-López et al., 2008). The PO serves as source for forebrain oligodentrocytes due to the high expression of Shh (García-López et al., 2008). Due to its transcriptional profile, the $\mathrm{POH}$ is considered as independent subdomain residing in the non-evaginated secondary prosencephalon (Flames et al., 2007; Moreno and González, 2011). While the PO expresses DLX2 as well as NKX2-1, the POH lacks NKX2-1 expression and expresses PAX6 instead (Flames etal., 2007; present data). In the embryonic brain, the $\mathrm{POH}$ constitutes the boundary that separates the subpallium from the hypothalamus, but it remains still unknown which cell population is derived from the $\mathrm{POH}$ in the adult brain. Our results reveal that in the human fetus NKX2-2 was detected in SVZ progenitor cells of along the AB boundary and the PVN. Furthermore, we detected NKX2-2-positive cells in SVZ precursors along the zona limitans intrathalamica (ZLI) and in the dorsal part of the lateral geniculate nucleus as well as in the ventromedial hypothalamic nucleus (not shown).

\section{THE PALLIAL-SUBPALLIAL BOUNDARY}

Data from the present study reveal that in the human brain the PSB proceeds dorsally of the expression domain DLX2 (separating the ventral pallium from the dLGE). While $\mathrm{POH}$ and $\mathrm{AB}$ boundary are rather gene expression domains than boundaries, the PSB is a true boundary. The PSB is the only segmental boundary that proceeds longitudinally and divides the telencephalon into a dorsal and ventral portion (Kiecker and Lumsden, 2012). The position of the PSB is determined by the mutual repression of PAX6 and GSX2 (a transcription factor which acts upstream of DLX2) since mutations in either of the two genes result in irregular PSB placement (Stoykova et al., 2000; Toresson et al., 2000; Yun et al., 2001; Carney et al., 2009; Cocas et al., 2011). The position of the PSB determines a local organizer referred as anti-hem assumed to counteract the cortical hem located at the dorsal margin of the pallium (Assimacopoulos et al., 2003; Hoch et al., 2009; Subramanian et al., 2009). Recently, the hem was described for human fetuses between 5 and 7 gestational weeks, whereas the anti-hem has not been identified in the human fetus, yet (Roy et al., 2013). Analysis of mouse PAX6 mutants (Sey-/-) which lack anti-hem signals reveal enhanced interneuron migration from the MGE to the pallium and abnormal corticothalamic projection. In the present study we observed migrating precursors derived from the PAX6-positive domain around the PSB (not shown) indicating that the anti-hem might also exist in the human fetal brain.

\section{MATURATION DYNAMICS IN THE HUMAN FOREBRAIN DIFFERS FROM RATS}

The development of the human cortex has been object of intensive research during the past three decades (Meyer et al., 2000; Bystron et al., 2006; Bayatti et al., 2008; Clowry et al., 2010; Molnár and Clowry, 2012). Cortical neurogenesis is initiated by the appearance of Reelin-producing Cajal-Retzius cells derived from the cortical hem system from 5 gestational weeks onwards (Meyer et al., 2000; Bystron et al., 2006). Migrating neural precursors from the PAX6positive SVZ migrate radially and divide the upper preplate into the outer marginal zone and the inner SP at 7-8 gestational weeks (Zecević, 1993; Meyer et al., 2000; Bystron et al., 2006). Our results show that SATB2-positive SP precursors were detected at $50 \mathrm{dpf}$ in the human brain, which coincides with results from previous studies (Clowry et al., 2010).

In turn, the development of the basal ganglia in the human brain is less well characterized. In the rodent brain, the majority of LGE-derived precursors will give rise to striatal projection neurons (Nakao et al., 1996; Stenman et al., 2003). Results from the present study reveal that immature striatal neurons are characterized by FOXP1 expression and can be detected already at $50 \mathrm{dpf}$. In turn, post-mitotic cells derived from the MGE giving rise to projection neurons of the GPe can be identified by NXK2-1 expression. Regarding the development of the human striatum, Carri et al. (2013) describes the expression pattern of several telencephalic transcription factors in the human fetus of 11 gestational weeks. The authors detected expression of early telencephalic transcription factors such as GSX2, OTX2, and FOXG1 in the SVZ of the LGE and detected post-mitotic striatal marker FOXP1\&2, CTIP2, and DARPP32 in the putamen and caudate nucleus at the same developmental stage (Carri et al., 2013). These data together with our results from the present study indicate that proliferation and neuronal maturation in the human striatum run in parallel during striatal neurogenesis. 


\section{RELEVANCE OF STRIATAL DEVELOPMENT FOR THE TREATMENT OF HUNTINGTON'S DISEASE}

Due to the pronounced loss of striatal projection neurons, HD has been targeted by cell therapeutic approaches (Rosser and Bachoud-Lévi, 2012). The concept of this therapy is the transplantation of ganglionic eminence precursor cells into the diseased striatum, where the cells replace degenerated striatal MSN and thereby reconstruct the damaged striatal output, mostly that into the GPe (Pauly etal., 2012; Trueman etal., 2012). Ganglionic eminence tissue derived from E13.0 to E16.0 rat fetuses grafted into a rat model of HD revealed that the best donor age lies around E14.0 which is coincides with the finding that cells for neural grafting must be obtained around the time point of peak neurogenesis (Olson et al., 1983; Watts et al., 2000; Schackel etal., 2013). Birth-dating experiments prior to and immediately after grafting revealed that striatal grafts are derived from both, dividing and post-mitotic precursor cells (Fricker-Gates et al., 2004). Our present data from human striatal development reveal that mitotic and post-mitotic precursors are present in the developing human ganglionic eminence during late embryonic stages, whereas mature DARPP32-positive MSN are missing.

For clinical transplantation trials on HD patients, donor tissue derived from 8 to 12 week old fetuses was mainly used (Kopyov et al., 1998; Bachoud-Lévi et al., 2000; Hauser et al., 2002; Rosser et al., 2002; Gallina etal., 2010, 2008). However, one of the unresolved questions is the optimal donor age for clinical transplantation (Freeman et al., 2011). The Carnegie Staging, typically consulted for developmental comparisons, favors the use of young donors (Carnegie Stage 19; 16-18.5 mm CRL; 43-46 dpf in humans; Streeter, 1942; O'Rahilly and Müller, 2006). However, our present data, as well as data from previous studies reveal that basal ganglia development in humans lasts over a longer period, thus rendering late embryonic stages more suitable for cell transplantation in HD (Clancy et al., 2001; Del Bigio, 2011; Carri et al., 2013).

\section{CONCLUSION}

In this study, we showed that the expression of regional restricted transcription factors in the developing human and rodent brain reveals a conserved pattern between in both species. In turn, rodents and humans differ in their neuronal differentiation dynamics. In the human fetus, proliferating precursors and postmitotic cells were detected to a high degree at the same time, indicating that these processes run in parallel during human brain development. In rat fetuses, proliferation and neuronal differentiation appear as sequential processes. These findings have direct influence on application of cell therapies for HD patients since the optimal donor age for grafting is not determined. The present study increases our understanding of forebrain development in humans and provides important new aspects for future cell therapy applications for HD.

\section{ACKNOWLEDGMENTS}

We thank Jessica Beckert, Mariana Klett, and Donata Maciaczyk for technical support. We also thank Professor Volker Coenen for his continuous support. The Pax6 antibody developed by
Atsushi Kawakami and the Nkx2-2 antibody (75.5A5) developed by Thomas M. Jessel and Susan Brenner-Morton were obtained from the Developmental Studies Hybridoma Bank developed under the auspices of the NICHD and maintained by The University of Iowa, Department of Biology, Iowa City, IA52242. This work was supported by grants of the German research foundation (DFG), the 7th framework program of the European Union (TRANSEURO) and the Hereditary Disease Foundation.

\section{REFERENCES}

Assimacopoulos, S., Grove, E. A., and Ragsdale, C. W. (2003). Identification of a Pax6-dependent epidermal growth factor family signaling source at the lateral edge of the embryonic cerebral cortex. J. Neurosci. 23, 6399-6403.

Bachoud-Lévi, A., Bourdet, C., Brugières, P., Nguyen, J. P., Grandmougin, T., Haddad, B., et al. (2000). Safety and tolerability assessment of intrastriatal neural allografts in five patients with Huntington's disease. Exp. Neurol. 161, 194-202. doi: 10.1006/exnr.1999.7239

Bardet, S. M., Ferran, J. L. E., Sanchez-Arrones, L., and Puelles, L. (2010). Ontogenetic expression of sonic hedgehog in the chicken subpallium. Front. Neuroanat. 4:28. doi: 10.3389/fnana.2010.00028

Bayatti, N., Moss, J. A., Sun, L., Ambrose, P., Ward, J. F. H., Lindsay, S., et al. (2008). A molecular neuroanatomical study of the developing human neocortex from 8 to 17 postconceptional weeks revealing the early differentiation of the subplate and subventricular zone. Cereb. Cortex N. Y. N 1991 18, 1536-1548. doi: 10.1093/cercor/bhm 184

Bulfone, A., Kim, H. J., Puelles, L., Porteus, M. H., Grippo, J. F., and Rubenstein, J. L. (1993). The mouse Dlx-2 (Tes-1) gene is expressed in spatially restricted domains of the forebrain, face and limbs in midgestation mouse embryos. Mech. Dev. 40, 129-140. doi: 10.1016/0925-4773(93)90071-5

Bystron, I., Rakic, P., Molnár, Z., and Blakemore, C. (2006). The first neurons of the human cerebral cortex. Nat. Neurosci. 9, 880-886. doi: 10.1038/nn1726

Carney, R. S. E., Cocas, L. A., Hirata, T., Mansfield, K., and Corbin, J. G. (2009). Differential regulation of telencephalic pallial-subpallial boundary patterning by Pax6 and Gsh2. Cereb. Cortex 19, 745-759. doi: 10.1093/cercor/ bhn 123

Carri, A. D., Onorati, M., Lelos, M. J., Castiglioni, V., Faedo, A., Menon, R., et al. (2013). Developmentally coordinated extrinsic signals drive human pluripotent stem cell differentiation toward authentic DARPP-32+ medium-sized spiny neurons. Development 140, 301-312. doi: 10.1242/dev. 084608

Clancy, B., Darlington, R. B., and Finlay, B. L. (2001). Translating developmental time across mammalian species. Neuroscience 105, 7-17. doi: 10.1016/S03064522(01)00171-3

Clowry, G., Molnár, Z., and Rakic, P. (2010). Renewed focus on the developing human neocortex. J. Anat. 217, 276-288. doi: 10.1111/j.1469-7580.2010.01281.x

Cobos, I., Shimamura, K., Rubenstein, J. L., Martínez, S., and Puelles, L. (2001). Fate map of the avian anterior forebrain at the four-somite stage, based on the analysis of quail-chick chimeras. Dev. Biol. 239, 46-67. doi: 10.1006/dbio. 2001.0423

Cocas, L. A., Georgala, P. A., Mangin, J.-M., Clegg, J. M., Kessaris, N., Haydar, T. F., et al. (2011). Pax6 is required at the telencephalic pallial-subpallial boundary for the generation of neuronal diversity in the postnatal limbic system. J. Neurosci. 31, 5313-5324. doi: 10.1523/JNEUROSCI.3867-10.2011

Corbin, J. G., Gaiano, N., Machold, R. P., Langston, A., and Fishell, G. (2000). The Gsh2 homeodomain gene controls multiple aspects of telencephalic development. Development 127, 5007-5020.

Del Bigio, M. R. (2011). Cell proliferation in human ganglionic eminence and suppression after prematurity-associated haemorrhage. Brain J. Neurol. 134, 1344-1361. doi: 10.1093/brain/awr052

Du, T., Xu, Q., Ocbina, P. J., and Anderson, S. A. (2008). NKX2.1 specifies cortical interneuron fate by activating Lhx6. Development 135, 1559-1567. doi: $10.1242 /$ dev. 015123

Elshatory, Y., and Gan, L. (2008). The LIM-homeobox gene Islet-1 is required for the development of restricted forebrain cholinergic neurons. J. Neurosci. 28, 3291-3297. doi: 10.1523/JNEUROSCI.5730-07.2008 
Evtouchenko, L., Studer, L., Spenger, C., Dreher, E., and Seiler, R. W. (1996). A mathematical model for the estimation of human embryonic and fetal age. Cell Transplant. 5, 453-464. doi: 10.1016/0963-6897(96)00079-6

Flames, N., Pla, R., Gelman, D. M., Rubenstein, J. L. R., Puelles, L., and Marín, O. (2007). Delineation of multiple subpallial progenitor domains by the combinatorial expression of transcriptional codes. J. Neurosci. 27, 9682-9695. doi: 10.1523/JNEUROSCI.2750-07.2007

Flandin, P., Kimura, S., and Rubenstein, J. L. R. (2010). The progenitor zone of the ventral medial ganglionic eminence requires $\mathrm{Nkx} 2-1$ to generate most of the globus pallidus but few neocortical interneurons. J. Neurosci. 30, 2812-2823. doi: 10.1523/JNEUROSCI.4228-09.2010

Freeman, T. B., Cicchetti, F., Bachoud-Lévi, A. C., and Dunnett, S. B. (2011). Technical factors that influence neural transplant safety in Huntington's disease. Exp. Neurol. 227, 1-9. doi: 10.1016/j.expneurol.2010.08.031

Fricker-Gates, R. A., White, A., Gates, M. A., and Dunnett, S. B. (2004). Striata neurons in striatal grafts are derived from both post-mitotic cells and dividing progenitors. Eur. J. Neurosci. 19, 513-520. doi: 10.1111/j.1460-9568.2004. 03149.x

Gallina, P., Paganini, M., Lombardini, L., Mascalchi, M., Porfirio, B., Gadda, D., et al. (2010). Human striatal neuroblasts develop and build a striatal-like structure into the brain of Huntington's disease patients after transplantation. Exp. Neurol. 222 30-41. doi: 10.1016/j.expneurol.2009.12.005

Gallina, P., Paganini, M., Lombardini, L., Saccardi, R., Marini, M., De Cristofaro, M. T., et al. (2008). Development of human striatal anlagen after transplantation in a patient with Huntington's disease. Exp. Neurol. 213, 241-244. doi: 10.1016/j.expneurol.2008.06.003

García-López, M., Abellán, A., Legaz, I., Rubenstein, J. L. R., Puelles, L., and Medina, L. (2008). Histogenetic compartments of the mouse centromedial and extended amygdala based on gene expression patterns during development. $J$. Comp. Neurol. 506, 46-74. doi: 10.1002/cne.21524

Hauser, R. A., Furtado, S., Cimino, C. R., Delgado, H., Eichler, S., Schwartz, S., et al. (2002). Bilateral human fetal striatal transplantation in Huntington's disease. Neurology 58, 687-695. doi: 10.1212/WNL.58.5.687

Hernández-Miranda, L. R., Parnavelas, J. G., and Chiara, F. (2010). Molecules and mechanisms involved in the generation and migration of cortical interneurons. ASN Neuro 2, e00031. doi: 10.1042/AN20090053

Hoch, R. V., Rubenstein, J. L. R., and Pleasure, S. (2009). Genes and signaling events that establish regional patterning of the mammalian forebrain. Semin. Cell Dev. Biol. 20, 378-386. doi: 10.1016/j.semcdb.2009.02.005

Jakovcevski, I., Mayer, N., and Zecevic, N. (2011). Multiple origins of human neocortical interneurons are supported by distinct expression of transcription factors. Cereb. Cortex 21, 1771-1782. doi: 10.1093/cercor/bhq245

Kiecker, C., and Lumsden, A. (2012). The role of organizers in patterning the nervous system. Annu. Rev. Neurosci. 35, 347-367. doi: 10.1146/annurev-neuro-062111 150543

Kopyov, O. V., Jacques, S., Lieberman, A., Duma, C. M., and Eagle, K. S. (1998). Safety of intrastriatal neurotransplantation for Huntington's disease patients. Exp. Neurol. 149, 97-108. doi: 10.1006/exnr.1997.6685

Lindsay, S., Sarma, S., Martínez-de-la-Torre, M., Kerwin, J., Scott, M., Luis Ferran, J. et al. (2005). Anatomical and gene expression mapping of the ventral pallium in a three-dimensional model of developing human brain. Neuroscience 136, 625-632. doi: 10.1016/j.neuroscience.2005.06.093

Marin, O., Anderson, S. A., and Rubenstein, J. L. (2000). Origin and molecular specification of striatal interneurons. J. Neurosci. 20, 6063-6076.

Martinez-Ferre, A., and Martinez, S. (2012). Molecular regionalization of the diencephalon. Front. Neurosci. 6:73. doi: 10.3389/fnins.2012.00073

Medina, L., Bupesh, M., and Abellán, A. (2011). Contribution of genoarchitecture to understanding forebrain evolution and development, with particular emphasis on the amygdala. Brain Behav. Evol. 78, 216-236. doi: 10.1159/000330056

Métin, C., Alvarez, C., Moudoux, D., Vitalis, T., Pieau, C., and Molnár, Z. (2007). Conserved pattern of tangential neuronal migration during forebrain development. Development 134, 2815-2827. doi: 10.1242/dev.02869

Meyer, G., Schaaps, J. P., Moreau, L., and Goffinet, A. M. (2000). Embryonic and early fetal development of the human neocortex. J. Neurosci. 20, 1858-1868.

Molnár, Z., and Clowry, G. (2012). Cerebral cortical development in rodents and primates. Prog. Brain Res. 195, 45-70. doi: 10.1016/B978-0-444-53860-4.00003-9

Moreno, N., and González, A. (2011). The non-evaginated secondary prosencephalon of vertebrates. Front. Neuroanat. 5:12. doi: 10.3389/fnana.2011.00012
Moreno, N., González, A., and Rétaux, S. (2008). Evidences for tangential migrations in Xenopus telencephalon: developmental patterns and cell tracking experiments. Dev. Neurobiol. 68, 504-520. doi: 10.1002/dneu.20603

Moreno, N., González, A., and Rétaux, S. (2009). Development and evolution of the subpallium. Semin. Cell Dev. Biol. 20, 735-743. doi: 10.1016/j.semcdb.2009.04.007

Nakao, N., Grasbon-Frodl, E. M., Widner, H., and Brundin, P. (1996). DARPP-32rich zones in grafts of lateral ganglionic eminence govern the extent of functional recovery in skilled paw reaching in an animal model of Huntington's disease. Neuroscience 74, 959-970.

Olson, L., Seiger, A., and Strömberg, I. (1983). Intraocular Transplantation in Rodents: A Detailed Account of the Procedure and Examples of its Use in Neurobiology with Special Reference to Brain Tissue. New York: Academic Press.

O'Rahilly, R. R., and Müller, F. (2006). The Embryonic Human Brain: An Atlas of Developmental Stages, 3rd Edn. Auflage: John Wiley \& Sons. doi: $10.1002 / 0471973084$

Pabst, O., Herbrand, H., Takuma, N., and Arnold, H. H. (2000). NKX2 gene expression in neuroectoderm but not in mesendodermally derived structures depends on sonic hedgehog in mouse embryos. Dev. Genes Evol. 210, 47-50. doi: 10.1007/PL00008188

Pauly, M.-C., Piroth, T., Döbrössy, M. D., and Nikkhah, G. (2012). Restoration of the striatal circuitry: from developmental aspects toward clinical applications. Front. Cell. Neurosci. 6:16. doi: 10.3389/fncel.2012.00016

Price, M. (1993). Members of the Dlx- and Nkx2-gene families are regionally expressed in the developing forebrain. J. Neurobiol. 24, 1385-1399. doi: $10.1002 /$ neu. 480241010

Puelles, L., and Rubenstein, J. L. R. (2003). Forebrain gene expression domains and the evolving prosomeric model. Trends Neurosci. 26, 469-476. doi: 10.1016/S0166-2236(03)00234-0

Robinson, G. W., Wray, S., and Mahon, K. A. (1991). Spatially restricted expression of a member of a new family of murine distal-less homeobox genes in the developing forebrain. New Biol. 3, 1183-1194.

Rosser, A. E., and Bachoud-Lévi, A.-C. (2012). Clinical trials of neural transplantation in Huntington's disease. Prog. Brain Res. 200, 345-371. doi: 10.1016/B978-0-444-59575-1.00016-8

Rosser, A. E., Barker, R. A., Harrower, T., Watts, C., Farrington, M., Ho, A. K., et al. (2002). Unilateral transplantation of human primary fetal tissue in four patients with Huntington's disease: NEST-UK safety report ISRCTN no 36485475. J. Neurol. Neurosurg. Psychiatry 73, 678-685. doi: 10.1136/jnnp.73.6.678

Roy, A., Gonzalez-Gomez, M., Pierani, A., Meyer, G., and Tole, S. (2013). Lhx2 regulates the development of the forebrain hem system. Cereb. Cortex. doi: 10.1093/cercor/bhs421 [Epub ahead of print].

Schackel, S., Pauly, M.-C., Piroth, T., Nikkhah, G., and Döbrössy, M. D. (2013). Donor age dependent graft development and recovery in a rat model of Huntington's disease: Histological and behavioral analysis. Behav. Brain Res. 256C, 56-63. doi: 10.1016/j.bbr.2013.07.053

Simeone, A., Acampora, D., Mallamaci, A., Stornaiuolo, A., D’Apice, M. R., Nigro, V., et al. (1993). A vertebrate gene related to orthodenticle contains a homeodomain of the bicoid class and demarcates anterior neuroectoderm in the gastrulating mouse embryo. EMBO J. 12, 2735-2747.

Stenman, J., Toresson, H., and Campbell, K. (2003). Identification of two distinct progenitor populations in the lateral ganglionic eminence: implications for striatal and olfactory bulb neurogenesis. J. Neurosci. 23, 167-174.

Stoykova, A., Treichel, D., Hallonet, M., and Gruss, P. (2000). Pax6 modulates the dorsoventral patterning of the mammalian telencephalon. J. Neurosci. 20, 8042-8050.

Streeter, G. L. (1942). Developmental horizons in human embryos. Description of age group XI, 13 to 20 Somites, and age group XII, 21 to 29 Somites. Carnegie Contrib. Embryol. 30, 211-245.

Subramanian, L., Remedios, R., Shetty, A., and Tole, S. (2009). Signals from the edges: the cortical hem and antihem in telencephalic development. Semin. Cell Dev. Biol. 20, 712-718. doi: 10.1016/j.semcdb.2009.04.001

Sussel, L., Marin, O., Kimura, S., and Rubenstein, J. L. (1999). Loss of Nkx2.1 homeobox gene function results in a ventral to dorsal molecular respecification within the basal telencephalon: evidence for a transformation of the pallidum into the striatum. Development 126, 3359-3370.

Terzić, J., and Saraga-Babić, M. (1999). Expression pattern of PAX3 and PAX6 genes during human embryogenesis. Int. J. Dev. Biol. 43, 501-508. 
Thal, L. J., Gilbertson, E., Armstrong, D. M., and Gage, F. H. (1992). Development of the basal forebrain cholinergic system: phenotype expression prior to target innervation. Neurobiol. Aging 13, 67-72. doi: 10.1016/0197-4580(92)90011-L

Tole, S., Remedios, R., Saha, B., and Stoykova, A. (2005). Selective requirement of Pax6, but not Emx2, in the specification and development of several nuclei of the amygdaloid complex. J. Neurosci. 25, 2753-2760. doi: 10.1523/JNEUROSCI.3014-04.2005

Toresson, H., Potter, S. S., and Campbell, K. (2000). Genetic control of dorsal-ventral identity in the telencephalon: opposing roles for Pax6 and Gsh2. Development 127, 4361-4371

Torres, E. M., Weyrauch, U. M., Sutcliffe, R., and Dunnett, S. B. (2008). A rat embryo staging scale for the generation of donor tissue for neural transplantation. Cell Transplant. 17, 535-542. doi: 10.3727/096368908785096006

Trueman, R. C., Klein, A., Lindgren, H. S., Lelos, M. J., and Dunnett, S. B. (2012). Repair of the CNS using endogenous and transplanted neural stem cells. Curr. Top. Behav. Neurosci. 15, 357-398. doi: 10.1007/7854_2012_223

Watts, C., Brasted, P. J., and Dunnett, S. B. (2000). Embryonic donor age and dissection influences striatal graft development and functional integration in a rodent model of Huntington's disease. Exp. Neurol. 163, 85-97. doi: 10.1006/exnr.1999.7341

Xu, Q., Tam, M., and Anderson, S. A. (2008). Fate mapping Nkx2.1-lineage cells in the mouse telencephalon. J. Comp. Neurol. 506, 16-29. doi: 10.1002/cne.21529

Yun, K., Garel, S., Fischman, S., and Rubenstein, J. L. R. (2003). Patterning of the lateral ganglionic eminence by the Gsh1 and Gsh2 homeobox genes regulates striatal and olfactory bulb histogenesis and the growth of axons through the basal ganglia. J. Comp. Neurol. 461, 151-165. doi: 10.1002/cne.10685

Yun, K., Potter, S., and Rubenstein, J. L. (2001). Gsh2 and Pax6 play complementary roles in dorsoventral patterning of the mammalian telencephalon. Development 128, 193-205.

Zecević, N. (1993). Cellular composition of the telencephalic wall in human embryos. Early Hum. Dev. 32, 131-149. doi: 10.1016/0378-3782(93)90007-H

Conflict of Interest Statement: The authors declare that the research was conducted in the absence of any commercial or financial relationships that could be construed as a potential conflict of interest.

Received: 18 October 2013; accepted: 23 December 2013; published online: 16 January 2014.

Citation: Pauly M-C, Döbrössy MD, Nikkhah G, Winkler C and Piroth T (2014) Organization of the human fetal subpallium. Front. Neuroanat. 7:54. doi: 10.3389/ fnana.2013.00054

This article was submitted to the journal Frontiers in Neuroanatomy.

Copyright (c) 2014 Pauly, Döbrössy, Nikkhah, Winkler and Piroth. This is an openaccess article distributed under the terms of the Creative Commons Attribution License (CC BY). The use, distribution or reproduction in other forums is permitted, provided the original author(s) or licensor are credited and that the original publication in this journal is cited, in accordance with accepted academic practice. No use, distribution or reproduction is permitted which does not comply with these terms. 